\title{
RANCANG BANGUN MOBIL LISTRIK SULA POLITEKNIK NEGERI SUBANG
}

\author{
Adhan Efendi ${ }^{1}$ ) \\ 1 Jurusan Teknik Perawatan dan Perbaikan Mesin, Politeknik Negeri Subang \\ Email: adhan@polsub.ac.id
}

\begin{abstract}
ABSTRAK
Mobil listrik merupakan salah satu kendaraan hemat energi yang saat ini banyak dikembangkan oleh perguruan tinggi di Indonesia. Salah satunya di Politeknik Negeri Subang. Penelitian ini bertujuan untuk membuat prototipe mobil listrik Sula Politeknik Negeri Subang. Jenis penelitian merupakan penelitian pengembangan. Pengambilan data melalui observasi dan dokumentasi pengerjaan praktik. Analisis data menggunakan deskriptif kualitatif. Hasil penelitian menunjukan (1) proses manufaktur mobil listrik sula dilaksanakan dengan tahapan pengerjaan, seperti membaca desain rancangan, pengukuran bahan, pemotongan bahan, assembly, dan uji kerja; (2) Hasil uji pengelasan terdapat indikasi cacat pengelasan seperti porosity dan undercut. Agar dapat mengurangi cacat las pada bagian cacat las porosity dilakukan pengelasan ulang dan lakukan pendempulan untuk merapikan dan melindungin karat pada hasil pengelasan. Hasil rangka mobil listrik sula dilakukan dengan uji jalan trak $1 \mathrm{~km}$ dan beban penumpang $50 \mathrm{~kg}$. Berdasarkan hasil penelitian dapat disimpulkan bahwa prototipe mobil listrik sula yang dibuat telah memenuhi standar untuk diikutkan dalam lomba mobil listrik Nasional.
\end{abstract}

Kata kunci: rancang bangun, mobil listrik sula, rangka dan suspensi

\begin{abstract}
Electric car mer Electric car is one of the energy-efficient vehicles currently being developed by universities in Indonesia. One of them in the Subang State Polytechnic is one of the energy-efficient vehicles currently being developed by universities in Indonesia. One of them is in Subang State Polytechnic. This study aims to make a prototype of the electric car Sula Subang State Polytechnic. This type of research is development research. Retrieval of data through observation and documentation of practical work. Data analysis using descriptive qualitative. The manufacturing process goes through several stages such as reading the design of the design, measuring the workpiece, cutting the workpiece, joining, assembling, and testing. This process is very supportive of the end result in manufacturing the main frame of the Sula electric car. The results showed (1) Sula's electric car manufacturing process is carried out with stages of workmanship, such as reading design designs, measuring materials, cutting materials, assembling, and working tests; (2) Welding test results indicate indications of welding defects such as porosity and undercut. In order to reduce welding defects in the porosity welding defect part, re-welding is done and puffing to smooth and protect the rust on the welding results The results of the Sula electric car frame were carried out with a $1 \mathrm{~km}$ trail test and a $50 \mathrm{~kg}$ passenger load. Based on the results of the study it can be concluded that the prototype of the electric car made by Sula has met the standards to be included in the National Electric Car Competition.
\end{abstract}

Keywords : manufacture, electric car, chasis and suspense)

\section{PENDAHULUAN}

Perkembangan sarana transportasi selalu mengalami perkembangan seiring dengan kemajuan jaman, salah satunya merupakan kendaraan menggunakan tenaga listrik sebagai tenaga penggerak utama. Mobil listrik merupakan kendaraan ramah lingkungan dan diharapkan mampu mengurangi penggunakan bahan bakar hasil minyak bumi atau fosil purba secara signifikan [1]. [2] beberapa kelebihan mobil listrik dengan mobil berbahan bakar cair adalah suara yang halus, tidak berbau, dan bebas dari asap. Ditambahkan oleh [3] bahwa mobil listrik dipandang sebagai mobil masa depan. Hal 
tersebut didasarkan dengan prediksi berkurangnya sumber daya alam di bumi, sehingga perlu diciptakannya sumber energi alternatif yang ramah lingkungan dan tidak terbatas.

Menurut [1] bahwa saat ini ada empat pilihan utama untuk transportasi alternatif: hibrida kendaraan, kendaraan sel bahan bakar hidrogen, bahan bakar bio, dan kendaraan listrik. Mobil listrik yaitu mobil yang digerakkan dengan motor listrik, menggunakan energi listrik yang disimpan dalam baterai [13]. Pengembangan mobil listrik saat ini sangatlah penting sebab pada zaman ini harga BBM sudah mulai malambung terus menerus. Adanya isu pemanasan global juga membuat manusia untuk berfikir bagaimana mengatasi permasalahan ini. Mobil listrik adalah suatu langkah yang "sekali dayung dua tiga pulau terlampaui" dengan arti melalui mobil listrik permasalahn Krisis energi akan bahan bakar fosfil dan pencemaran lingkungan dapat teratasi dengan hadirnya mobil listrik ini.

Kendaraan mobil listrik di Indonesia mengalami perkembangan yang pesat terutama dikalangan mahasiswa perguruan tinggi dengan adanya kompetisi untuk membuat kendaraan yang layak dipasarkan. Salah satu kompetisi yang diadakan di Indonesia yaitu Kontes Mobil Listrik Indonesia (KMLI), Mobil Hemat Energi (KMHE), Indonesia Energy Marathon Challenge (IEMC) untuk tingkat Nasional dan Shell Eco Marathon (SEM) untuk tingkat Internasional kompetisi perguruan tinggi. Hasil penelitian [14] menyatakan bahwa banyak perguruan tinggi yang sudah memiliki kendaraan listrik seperti mobil Politeknik Bandung, mobil listrik Garuda UNY, mobil listrik simadu Universitas Subang, mobil listrik batman ITS, dan mobil listrik pempek Universitas Sriwijaya Palembang. Untuk menjaga kondisi mobil listrik agar mobil listrik dapat digunakan sebagai media pembelajaran pada pada bidang pendidikan vokasional.

Ide penelitian ini berlandaskan dibutuhkan sebuah mobil hemat energi, tidak menimbulkan emisi gas buang yang berbahaya untuk lingkungan, serta sesuai dengan standar kompetisi mobil listrik Indonesia (KMLI). Pada penelitian sebelumnya, [13] bahwa proses rancang bangun mobil listrik dibutuhkan sebuah rangka mobil yang berfungsi sebagai penopang semua beban yang ada pada kendaraan, untuk sebuah kontruksi rangka itu sendiri harus memiliki standar kekuatan, ringan dan mempunyai nilai kelenturan. Diperjelas oleh [12] bahwa mobil listrik harus efektif serta menjadi solusi utama dalam upaya mencegah kerusakan lingkungan dari kendaraan yang menggunakan bahan bakar cair. diperjelas oleh penelitian [9] bahwa pasar otomotif dunia merespon baik mengenai pembuatan mobil listrik dengan skala besar, hal tersebut dikarenakan mobil listrik lebih ramah lingkungan dibandingkan mobil dengan bahan bakar bensin.

Penelitian mengenai rancang bangun mobil listrik pada penelitian sebelumnya sudah banyak dilakukan. Permasalahan yang dihadapi oleh peneliti dalam mengembangkan prototipe mobil listrik adalah proses pembuatan mobil listrik menggunakan alat seadanya dari kampus, sehingga hasil dari penelitian tersebut hanya sebatas membuat prototipe tanpa ada kelanjutan mau diapakan prorotipe mobil listrik tersebut [15]. Namun sebagian besar penelitian yang dilakukan hanya membuat rancangan desain gambar 3D saja, belum sampai proses membuat mesin (manufaktur). Politeknik Negeri Subang merupakan perguruan tinggi dengan status binaan. Berdasarkan hal tersebut, peneliti tertartik untuk membuat mobil listrik yang ramah terhadap lingkungan serta dapat diikutsertakan dalam kompetisi mobil tingkat nasional. 


\section{METODE}

Jenis penelitian merupakan penelitian pengembangan. Pengambilan data melalui observasi dan dokumentasi pengerjaan praktik. Analisis data menggunakan deskriptif kualitatif. Proses pembuatan rangka mobil listrik dilakukan di bengkel teknik perawatan dan perbaikan mesin Politeknik Negeri Subang. Waktu pengerjaan dilaksanakan dalam jangka waktu tujuh (7) bulan yaitu dari bulan Desember - Juli 2019. Jenis penelitian ini merupakan penelitian research dan development (R\&D). Tahapan penelitian dalam proses manufaktur adalah sebagai berikut:

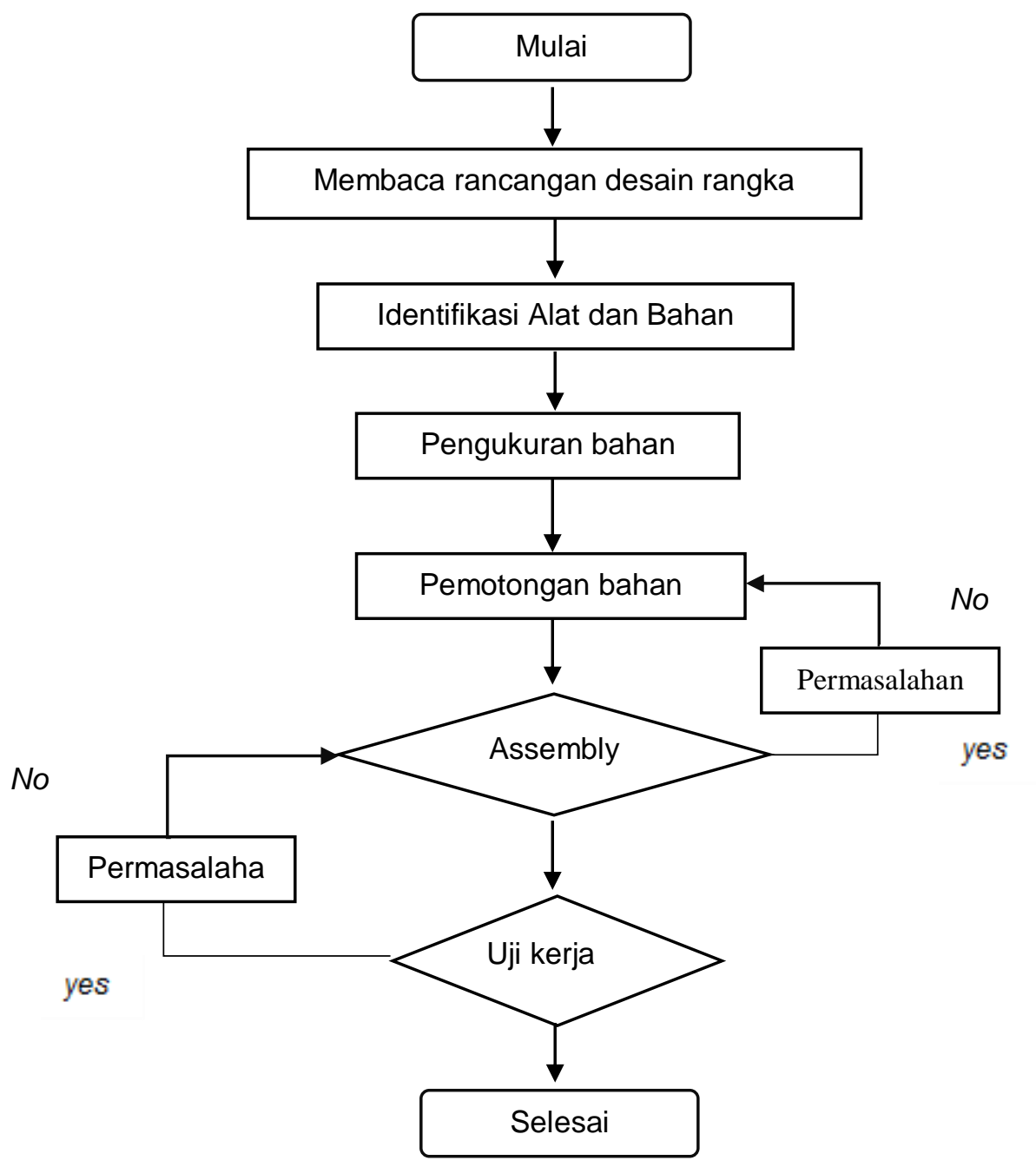

Gambar 1. Tahapan penelitian

Tahapan pertama yang dilakukan adalah membaca desain rancangan kerangka merupakan hal utama yang perlu dilakukan sebelum proses pengerjaan shasis. Proses ini bertujuan untuk memudahkan dan meminimalisir problem yang terjadi saat proses pengerjaan sehingga mendapatkan hasil yang sesuai dengan desain rancangan kerangka; menyiapkan dan mengidentifikasi alat dan bahan yang diperlukan utuk menunjang pengerjaan dengan udah dan sesuai dengan klasifikasi yang di perlukan pembuatan shasis. Bahan yang digunakan yaitu pipa baja hitam atau carbon steel pipe, elektroda RD-260, plat stainless steel. Pralatan mesin yang digunakan yaitu mesin gerinda tangan, mesin las, mesin bor tangan; proses pengerjaan pembuatan kerangka mobil listrik memerlukan beberapa tahap secara runtut agar mendapakan hasil sesuai desain dan mengurangi kesalahan dalam peroses pengerjaan; uji kerja merupakan tahap akhir dalam proses pengerjaan yang bertujuan untuk memeriksa hasil kinerja atau uji jalan pada suatu mesin atau alat tertentu. Teknik pengambilan data melalui observasi dan dokumentasi. Observasi dan dokumentasi dilakukan selama proses 
pembuatan prototipe mesin listrik sula. Data yang didapatkan kemudian di analisis secara kualitatif deskriptif. Proses manufaktur didasarkan pada work preparation (WP) yang telah dibuat oleh tim peneliti. Penggunaan WP menjadi dasar atas proses yang akan dikerjakan dalam merancang bangun mobil listrik SULA.

\section{HASIL DAN PEMBAHASAN}

\section{A. MEMBACA RANCANGAN DESAIN}

Rancangan desain mobil listrik sula di gambar melalui aplikasi autodeks inventor. Output yang dihasilkan berupa gambar 3D dari komponen rangka dan suspensi mobil sula secara detail.

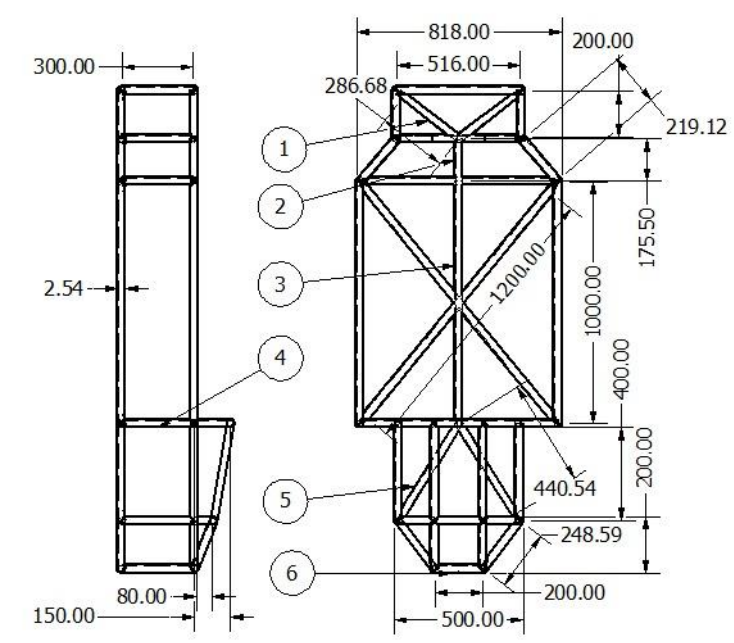

Gambar 2. Rancangan desain
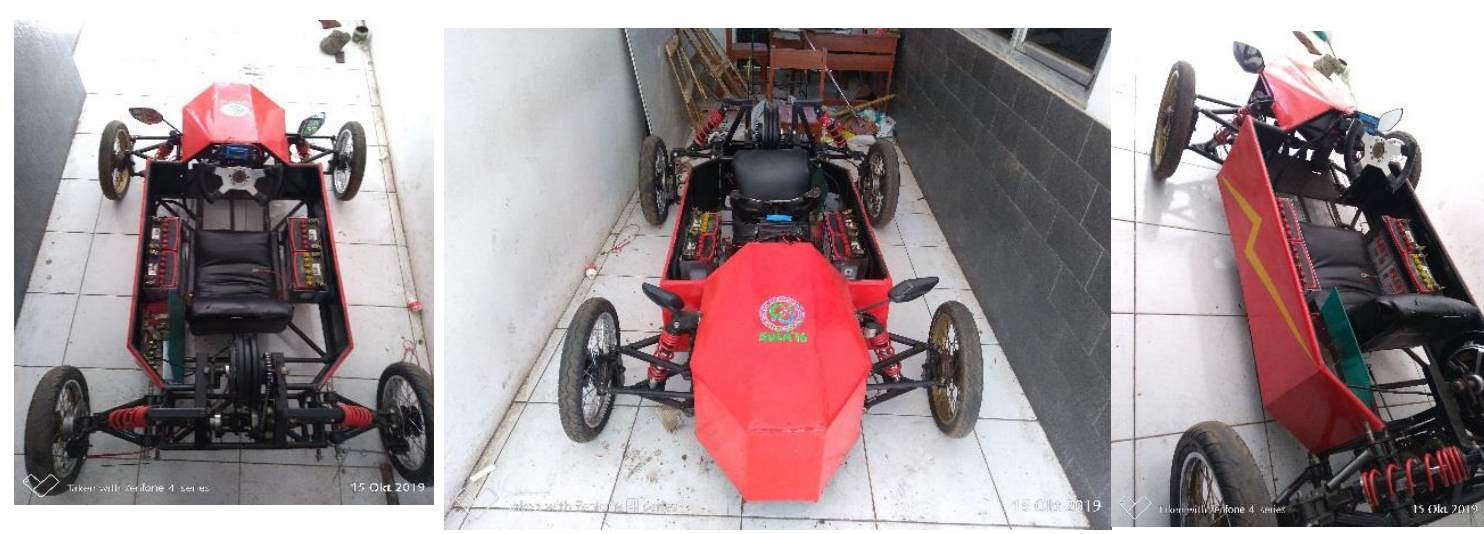

Gambar 3. Mobil sula politeknik negeri subang 


\section{B. IDENTIFIKASI ALAT DAN BAHAN}

Tabel 1. Alat dan bahan

\begin{tabular}{cc}
\hline \multicolumn{1}{c}{ Komponen yang dibutuhkan } \\
\hline Alat & Bahan \\
Mesin Gerinda & Besi Pipa \\
Mesin Las SMAW & Besi Hollow \\
Mesin Bubut & Elektroda Las \\
Meteran & Baut dan Mur \\
Penyiku & Besi Plat \\
Jangka Sorong & Bearing Fhs \\
Busur Derajat & Shock Breaker \\
Kunci Shock & Bearing \\
Ragum & Mata Gerinda \\
Penitik & Mata Bor \\
APD & Amplas \\
\hline
\end{tabular}

\section{PROSES MANUFAKTUR}

Proses pengukuran rangka utama dilakukan sesuai rancangan desain. Proses manufaktur pada mesin mobil listrik menjadi hal utama yang harus diperhatikan. Menurut [12] proses manufaktur pada mesin hemat energi dibutuhkan untuk mengurangi beban kendaraan serta mobil listrik harus mempunyai tempat khusus untuk peletakan baterai. Pada mobil listrik baterai menjadi sumber tenaga utama kendaraan. Pengerjaan mengukur besi pipa menggunakan roll meter serta dilakukan pengukuran besi untuk rangka utama. Teori dasar pembuatan rangka mobil listrik menurut [13] yaitu (1) rangka harus kuat dan kokoh, sehingga mampu menopang mesin beserta kelengkapan kendaraan lainnya,bmenyangga penumpang maupun beban tanpa mengalami kerusakan atau perubahan bentuk; (2) ringan, sehingga tidak terlalu membebani mesin (meningkatkan efektivitas tenaga yang dihasilkan mesin). Berdasarkan teori tersebut, kemudia peneliti melakukan pengukuran dibagi menjadi tiga bagian, yaitu depan, tengah dan belakang. Untuk memudahkan pemotongan dan pengerjaan ukur bagian tengah terlabih dahulu, pengukuran besi pipa dengan panjang $1000 \mathrm{ml} 5$ batang, $818 \mathrm{ml} 4$ batang, $600 \mathrm{ml} 4$ batang, $300 \mathrm{ml} 4$ batang. Kemudian bagian belakang dengan panjang $516 \mathrm{ml} 3$ batang, $200 \mathrm{ml} 4$ batang, $219 \mathrm{~cm} 4$ batang,287 $\mathrm{ml} 2$ batang, dan $176 \mathrm{ml} 1$ batang. Kemudian bagian depan dengan panjang $500 \mathrm{ml} 1$ batang, $200 \mathrm{ml} 4$ batang, $400 \mathrm{ml} 6$ batang, $249 \mathrm{ml}$, 4 batang, dan 445 $\mathrm{ml} 2$ batang. Ditambahkan oleh [9] bahwa dalam merancang rangka utama perlu juga diperhatikan bentuk kendaraan yang mempengaruhi ergonomis mobil listrik. Dtambahkan oleh [11] bahwa diperlukan pembuatan mesin kendaraan dengan keseimbangan antara titik beban utama agar kendaraan dapat melaju secara optimal.

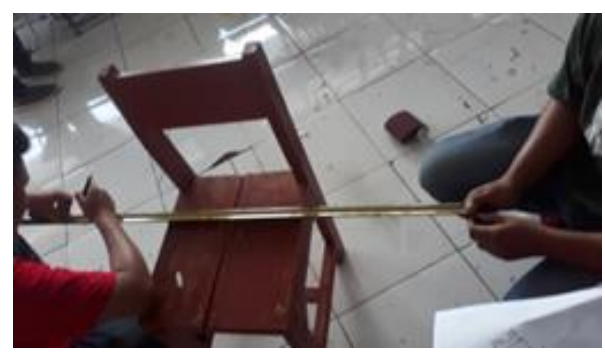

Gambar 4. Pengukuran pipa

Setelah rangka tengah sudah di ukur dan diberi tanda, kemudian potong besi pipa yang sudah ditandai dengan mesin gerinda menggunkan batu gerinda potong, Sebelum itu gunakan perlengkapan alat pelindung diri (APD). APD merupakan standar dalam proses pengerjaan praktik [4]. 


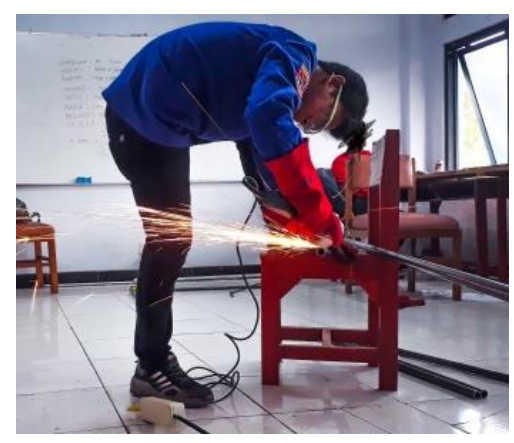

Gambar 5. Pemotongan pipa

Setelah bahan sudah terpotong sesuai ukuran, Kemudian membuat cetakan sudut $45^{\circ}$ dengan ampelas. bentuk sudut $45^{\circ}$ sesuai dengan cetakan pada bagian kedua ujung besi dengan gerinda tangan

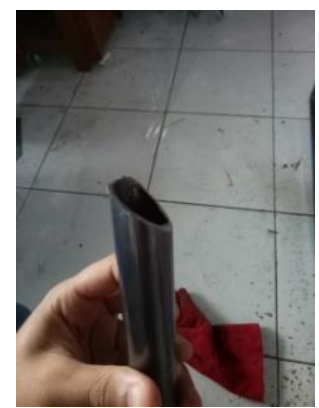

Gambar 6. Pembentukan sudut

Pengerjaan selanjutnya dengan melakukan pengelasan menggunakan mesin las SMAW dengan elektroda RD260 agar ringan dan mudah saat pengelasan pada proses penyambungan pada pipa. Peneliti menggunakan amper 65 sampai 70 agar busur tidak jebol/bolong. Gerinda bagian ujung yang akan di las untuk membersihkan kotoran atau karat pada besi pipa, lakukan pengelasan secara teg wel. Lakukan penyambungan dengan membuat bagian rangka lengan terlebih dahulu. Ditambahkan oleh [5] proses pengelasan harus didasari dengan tata penggunaan alat dan bahan yang sesuai standar keamanan kesehatan dan keselamatan kerja (K3).

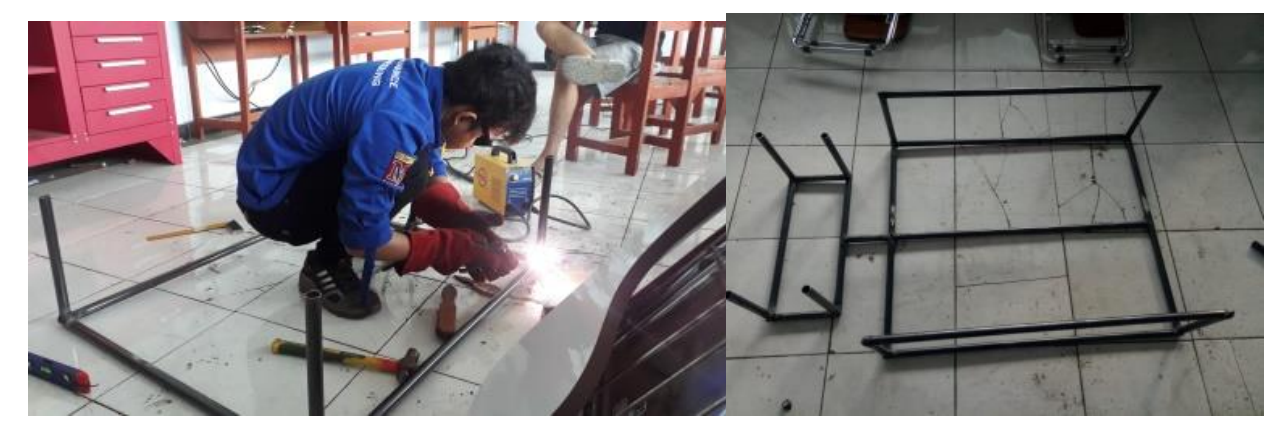

Gambar 7. Proses pengelasan

Hasil pngelasan tag wel, ukur menggunakan penggaris sikut untuk mengukur posisi tegak lurus atau sudut $90^{\circ}$. Apabila terjadi kemiringan pada hasil pengelasan, pikil besi menggunakan palu hingga lurus atau sejajar dengan penggaris siku. 


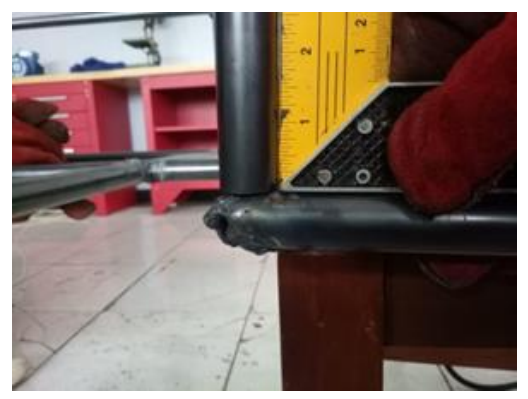

Gambar 8. Hasil pengelasan

Setelah bagian lengan selesai dikerjakan, kemudian proses penyambungan dilakukan pada bagian belakang mobil listrik. Busur derajat digunakan untuk meningkatkan ketelitian dalam mengukur sudut yang berbeda-beda. Ditambahkan oleh [10] hasil proses pengelasan harus dilakukan pengujian penetran. Pengujian dimaksudkan untuk melihat kualitas dan kekuatan proses penyambungan yang telah dilakukan.

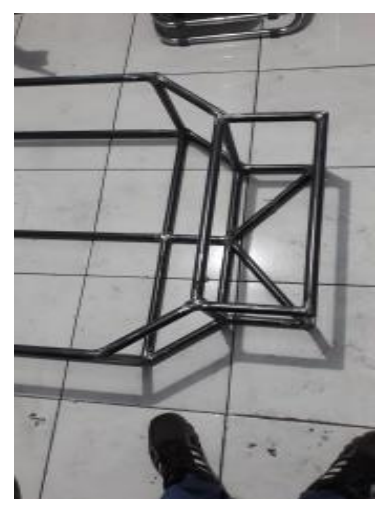

Gambar 9. Rangka utama

Langkah selanjutnya tim peneliti melakukan pengelasan pada bagian rangka depan. Di perjelas oleh [11] bahwa pembuatan rangka mobil listrik harus dapat mengurangi drag/hantaman angin sehingga perlu diperhatikan berat dan ergonomisnya. Gunakan amper redah kisaran 65 untuk mengelas bagian sudut untuk mengurangi cacat porosity atau bolong pada hasil las. Gunakan penggaris siku dan busur derajat untuk mengukur sudut yang diperlukan.

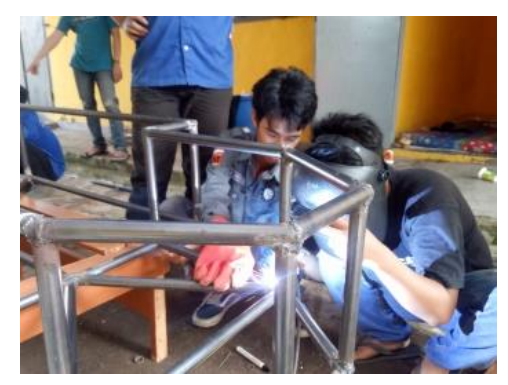

Gambar 10. Rangka depan

Setelah proses pengelasan pada keseluruhan bagian selesai, terbentuklah rangka utama pada mobil listrik sula. Rangka ini berupa rangka dasar mobil, tidak mencangkup dengan dudukan motor, sistem kemudi, dan tempat duduk pengemudi. Kerangka kendaraan merupakan rangka yang berfungsi sebagai penompang beban penumpang serta beban komponen pada mobil [7]. 


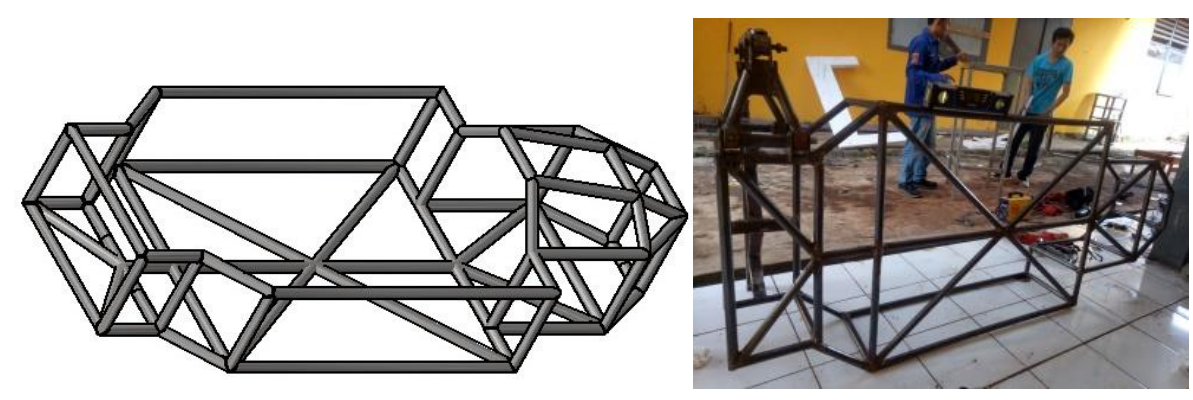

Gambar 11. Hasil Rangka Mobil Sula

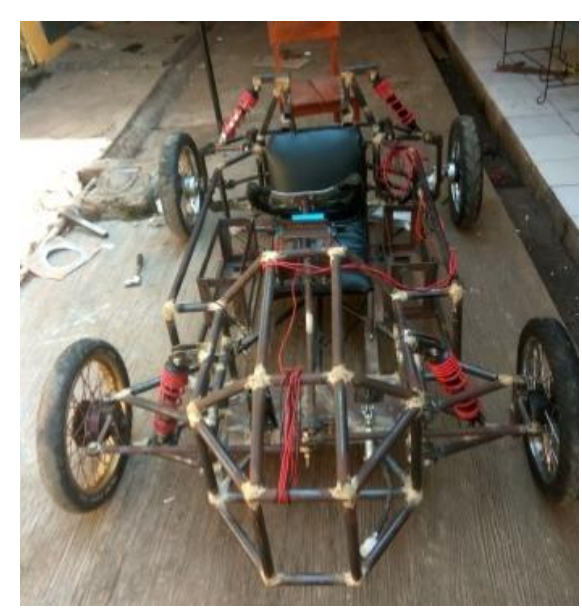

Gambar 12. Prototipe Mobil Sula

\section{UJI KINERJA}

Pengujian ini bertujuan untuk mengetahui indikasi cacat hasil pengelasan pada permukaan benda. Dalam pengujian ini, pada bagian titik tumpu atau bagian tengah rangka diambil sebagian sempel pengujian penetran. Ditambahkan oleh [10] bahwa diperlukan variasi arus akan mempengaruhi hasil lasan yang kerjakan. Hasil dari pengujian ini terdapat indikasi cacat pengelasan seperti porosity dan undercut. Untuk mengurangi cacat las. pada bagian cacat las porosity dilakukan pengelasan ulang, dilakukan pendempulan untuk merapikan dan melindungi karat pada hasil pengelasan. Pada rangka dilakukan proses pengujian beban penumpang $80 \mathrm{~kg}$ dengan uji jalan 10 meter. Ditambahkan oleh [6] dibutuhkan energi spesifik yang lebih tinggi memungkinkan massa baterai lebih rendah dan lebih sedikit energi yang diperlukan daya kendaraan. Ditambahkan oleh [8] bahwa uji kinerja dilakukan dalam upaya melihat kekurangan alat atau mesin yang telah melalui proses manufaktur. Pengujian penetran berdasarkan penelitian pendukung diatas diharapkan mampu melihat dan mendeteksi kecacatan yang terjadi dalam proses pengelasan rangka mobil listrik SULA. Hal tersebut juga didasarkan pada hasil penelitian [13] rangka mobil listrik yang sesuai standar memiliki syarat berupa ringan, kuat, dan memiliki kelenturan. Hal tersebut, diharapkan mampu menciptakan prototipe mobil listrik yang memiliki kecepatan dan kekuatan. 


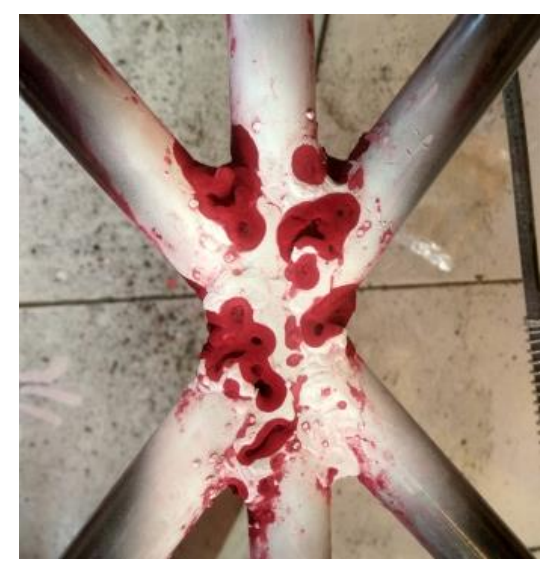

Gambar 13. Pengujian pengelasan

\section{SIMPULAN DAN SARAN}

Berdasarkan hasil penelitian dapat dismpulkan:

1. Proses manufaktur mobil listrik sula dilaksanakan dengan tahapan pengerjaan, seperti membaca desain rancangan, pengukuran bahan, pemotongan bahan, assembly, dan uji kerja.

2. Hasil uji pengelasan terdapat indikasi cacat pengelasan seperti porosity dan undercut. Agar dapat mengurangi cacat las pada bagian cacat las porosity dilakukan pengelasan ulang dan lakukan pendempulan untuk merapikan dan melindungin karat pada hasil pengelasan

Saran: diperlukan analisis perhitungan ergonomis dan drag/hantaman angin untuk mengurangi kerugian yang terjadi pada mobil listrik sula. Berisi simpulan dan saran. Simpulan memuat jawaban atas pertanyaan penelitian. Saran-saran mengacu pada hasil penelitian dan berupa tindakan praktis, sebutkan untuk siapa dan untuk apa saran ditujukan. Ditulis dalam bentuk essay, bukan dalam bentuk numerikal.

\section{UCAPAN TERIMAKASIH}

Terima kasih kepada civitas akademika di jurusan Pemeliharan Mesin Politeknik Negeri Subang dan redaksi Jurnal JPTK Universitas Pendidikan Ganesha yang telah memberikan kesempatan untuk publikasi.

\section{DAFTAR PUSTAKA}

[1] M. J. Nyaga, "Developing And Building A Prototype Rear Wheel Drive Electric Car," no. May, (2009).

[2] C. O. Quandt and S. Innovation, "Manufacturing the electric vehicle: a window of technologica opportunity for Southern California," no. February 1995, (2014).

[3] A. Guizani, M. Hammadi, J. Choley, and T. Soriano, "M echanics I ndustry Electric vehicle design , modelling and optimization," no. March, (2016).

[4] A. Efendi and Y. S. Nugroho, "Has the Electrical Laboratory of Subang State Polytechnic Applied," vol. 2, no. 2, pp. 47-52, (2019).

[5] K. A. Efendi; D, "Evaluation of the Application of Occupational Safety and Health (OSH) at the Subang State Polytechnic Lab," Automot. Exp., vol. 2, no. 1, pp. 9-14, (2019).

[6] S. Carlos, A. De Almeida, and F. Vieira, "Modeling and Analysis of an Electric Vehicle using PAMVEC COBEM-2017-1852 MODELING AND ANALYSIS OF AN ELECTRIC VEHICLE USING," no. December 2017, (2018).

[7] Ary Fadilah, Bustami Syam. "analisis simulasi struktur chassis mobil usu berbahan besi struktur terhadap beban statik dengan menggunakan perangkat lunak ansys 14.5." 6 (2013).

[8] A. Efendi, A. Nugraha, dan R.Baharta. "Manufacturing Of Electrical Dryer Machine For Food And Fruit Products. IOP Conf. Series: Materials Science and Engineering 692 (2019).

[9] Carlos O... "Manufacturing the electric vehicle: a window of technological opportunity for Southern California. Environment and Planning A, volume 27, pages 835-862 (1995). 
[10] Tumpal Ojahan R, Ferry Mahardika Putra, Yusup Hendronursit. "Analisa Variasi Arus Menggunakan Las Gtaw pada Material Ss Jis410j1 Dengan Filler Er308L". Jurnal Rekayasa, Teknologi, dan Sains, Volume 2 Nomor 1, Januari (2018).

[11] Agung Premono, Ahmad Kholil, Hafidz Salafuddin. "Desain Dan Analisis Kekuatan Pada Rangka Kendaraan Jenis Prototype Sesuai Standar Shell Eco Marathon Asia", Universitas Negeri Jakarta, (2019).

[12] Anang Dasa Novfowan, "Mobil Listrik Tantangan Masa Depan”, Majalan Bistek Edisi 06.Jakarta, 1998.

[13] Marlia Adriana, Anggun Angkasa, dan Masrianor, "Rancang Bangun Rangka (Chasis) Mobil Listrik Roda Tiga Kapasitas Satu Orang”. Jurnal Elemen Volume 4 Nomor 2, Desember (2017).

[14] A. Efendi dan Azhis S.B. "Pemeliharaan Mobil Listrik SULA Politeknik Negeri Subang", Jurnal Rekayasa Mesin. Vol 14, No. 3, Desember (2019).

[15] Lilis Setiono, "Perancangan Mekanika Dan Realisasi Kontrol Mobil Listrik" e-Proceeding of Engineering : Vol.3, No.3 Desember (2016). 